\title{
Introduction to the Festschrift
}

\author{
Louis Keith \\ The Department of Obstetrics and Gynecology, Northwestern University Medical School, and The Center for Study of Multiple Birth, USA
}

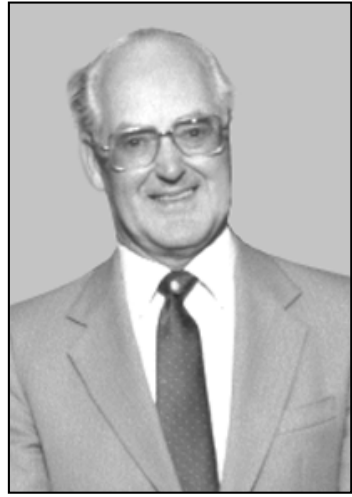

The curious reader may wonder about the purpose of this "Festschrift" and the origins of this word. The fact that this word is German pro-

vides an important clue. In the late 19th and early 20th centuries, "Festschrifts" were not uncommonly produced to accompany "Festags", special days of celebration in the academic world when the lingua franca was German rather than English. Indeed, during these same years many important works on twinning were written in German, starting with the seminal descriptions of monochorionic twin placentation by Schatz and continuing with numerous anthropometric studies by von Verschuer before the Second World War.

The term "Festag" is easily translated into "Festive Day", a term often used on the occasion on a professor's retirement or some other special occasion. The companion term, "Festschrift", is the written transcript, as it were, of the proceedings of that special occasion. In the case of the Working Group on Multiple Pregnancy of the International Society of Twin Studies, the "Festag" will be on July 3, 2001 in honor of the 80th birthday of Professor Ian MacGillivray, the first chairman of the Working Group. It was he who organized the initial meeting of this group in Aberdeen, Scotland. At that time, little did Professor MacGillivray or the members of his audience know this modest gathering would be the forerunner of a long series of meetings in which obstetricians and gynecologists from around the world would gather to discuss important problems and later publish their observations.

Similarly, it might be said that I had no thought of ultimately succeeding to the chairmanship of the Working Group when Professor MacGillivray reached the age of 65 and subsequently passing the baton on the occasion of my 65th birthday. In my case, the baton goes to Professor Isaac Blickstein of Israel, a worthy successor by any standard and a pre-eminent expert in multiple births.

The three of us will be present in London on the occasion of the Triennial Meeting of the International
Society of Twin Studies, when the Working Group presents a one-day symposium on Multiple Pregnancy preceding the general sessions of the Society. This workshop will address the urgent topics of 2001. These include the epidemiology of multiple birth, the continuing problems of zygosity determination, the perpetual inability of the medical profession to prevent low birthweight, preterm multiple deliveries, the growing awareness that the mother of multiples is also at risk along with her children, the manifold problems of understanding twin placentation and the difficulties in deciding an ideal method for delivery of multiples. The workshop will conclude with advice for caregivers and a survey of the existing controversies.

Without doubt, such topics as those listed above would have been unthinkable at the time of the first workshop in Aberdeen. At that time, the participants represented a handful of zealots who, for one reason or the other, found the arcane subject of multiple pregnancy interesting enough to make their way to Aberdeen and listen to other similarly inclined individuals. None of us could envision that our chosen topic would become front-page news by the end of the century and that the numbers of twins and other multiples would increase so dramatically that the term "epidemic" would be used to describe this change. Similarly, none of us could envision the fact that the then newly available contraceptives could affect the age of child bearing worldwide or that powerful drugs could be devised which would cause multiple ovulations and make higher-order multiple pregnancy commonplace. So much for our ability to foretell what was going to happen to our profession and to our special interest.

It now seems reasonable that those who follow us at the 10th triennial congress will not only have to deal with IVF and ART but cloning in addition to all the problems mentioned by the speakers in the "Festag".

Address for correspondence: Louis G. Keith, M.D., 333 East Superior Street, Chicago IL 60611, USA. E-mail:lgk395@northwestern.edu 
Thus, Professor MacGillivray's "Festag" may at some future time be regarded as a bridge between medicine as it was practiced in the 20th century and medicine as it will be practiced in the 21 st century. Under these circumstances, we can only hope that future readers will understand our desire to honor one of the 20th century's leading obstetricians on the occasion of his 80th birthday. Clearly, Professor MacGillivray's life and work has been and continues to be an inspiration for many who will sit in the audience in London. Let us hope that our comments and our work will also inspire those who come after us. 